\title{
Short-Run Cost Minimization and Capacity Utilization of Regional Public Hospitals in South Korea
}

\author{
Sang-Mok Kang, Moon-Hwee Kim \\ Department of Economics, Pusan National University, Busan, South Korea \\ Email: smkang@pusan.ac.kr, moonhwee@gmail.com
}

Received 24 November 2014; revised 15 December 2014; accepted 25 December 2014

Copyright $@ 2015$ by authors and Scientific Research Publishing Inc.

This work is licensed under the Creative Commons Attribution International License (CC BY). http://creativecommons.org/licenses/by/4.0/

cc) (i) Open Access

\begin{abstract}
This paper intends to obtain the short-run average cost minimization and capacity utilization over 34 regional public hospitals in South Korea from 2007 to 2010 using Data Envelopment Analysis (DEA). Also, it explores the average cost for each hospital in order to determine whether the cost is increasing or decreasing. The annual capacity utilization rate, using an adjusted number of patients as an output, was 0.49 , and by using value added as an output was 0.56 , on average. Only Jeju showed the highest level of capacity utilization regardless of output type. It indicates that almost all regional public hospitals, except for Jeju, have not run with full capacity, and have been in the decreasing area in the short-run average cost curve during the same period.
\end{abstract}

\section{Keywords}

Regional Public Hospitals, Cost Minimization, Capacity Utilization, Data Envelopment Analysis

\section{Introduction}

According to an OECD (Organization for Economic Cooperation and Development) report (2013) [1], the annual growth rate of the total health expenditure of South Korea (9.8\%) was much higher than that of OECD average (4.8\%) from 2000 through 2009, even though the annual growth rate of Korea decreased from 2010 through 2011 (4.7\%) compared to that in the previous period, it is much higher than that of OECD average $(0.6 \%)$. The public health expenditure as well as the total health care expenditure in South Korea have been steadily increased annually since 2000. In addition, governments in many countries have tried to cut their spending on health care, especially in the public health sector (OECD, 2013).

Recently, the hottest issue in the public health sector has been the closure of Jinju Medical Center in South 
Korea. South Gyeongsang provincial government shut down Jinju Medical Center (JMC), a provincial public general hospital, despite strong opposition from its unionized workers. Similarly, many regional public hospitals have been facing difficulties such as accumulated debts, unpaid wages, outdated facilities, and a labor shortage.

When it comes to a result-oriented economic performance for hospitals, the issue of efficiency is considered as an important matter. However, in the short-run, the hospitals are also required to produce the maximum amount of outputs such as treatment of patients or value added under fixed factors as an example capital stock, land, and other fixed costs. Thus, it is meaningful to check whether or not these hospitals operate with an acceptable level of capacity utilization based on the cost minimization. Moreover, it would be also useful to learn the scale efficiency of each hospital to examine if the hospital runs at an optimal scale.

Many economists have recently tried to define capacity utilization; which is divided into physical and economic definitions of capacity. In general, capacity is referred to the most efficient level of output, and it indicates economic capacity, which is different from an engineering or technical maximum output. Technical maximum is not based on cost concerns however the economic capacity concept takes into account economic cost.

The capacity utilization usually refers to capacity utilization rates, and is called an operating rate. It represents the relationship between actual output and potential output that could be achieved with labor force and capital stock. This is shown in a percentage rate; one hundred (100) percent implies full capacity. If a hospital operates at a $70 \%$ capacity utilization rate, it illustrates that there is a possibility to improve its production by 30 percent without additional fixed costs, such as the cost of building a new facility. In this sense, as stated previously, it is meaningful to check the capacity utilization rate for each regional public hospital in order to increase its feasible improvement as a production unit.

While the economic concept of maximum output is based on Klein's or Johansen's definition employing a production function, from an engineering perspective, the capacity is simply rated one.

One of the earliest discussions of capacity measurement is provided by Cassels (1937) [2], defining that excess capacity is sometimes used to describe fixed factors of decision making units (DMUs) such as firms, industries or organizations. It is simultaneously used with respect to all the factors included in the functioning of DMUs in the short and long run cost curve. Klein (1960) [3] expanded the engineering notion of capacity and determined the economic concept of a production function in order to explain the notion of maximum output as an index combination of all fully utilized factors, considering not only capital stock but also other determinable factors. While Johansen (1968) [4] defines it as: "maximum amount that can be produced per unit of time with existing plant and equipment provided the availability of variable factors of production is not limited”, Färe (1984) [5] determined a weak definition of capacity which only requires that output is limited. Färe and Grosskopf and Kokkenlenberg (1989) [6] measured estimates of plant capacity and utilization rates by Johansen's definition using frontier, rather than "average” production functions. Eilon and Soesan (1976) [7] suggest that the construction of a full capacity envelope curve, which defines the maximum possible output levels for each output mix, which is closely related to the radial (output-oriented) technical efficiency measures proposed by Farrell (1957) [8] and the distance function measures proposed by Shephard (1970) [9]. Many economists have searched for more economically meaningful measures of capacity, and Berndt and Morrison (1981) [10] turned to short-run cost functions for guidance.

In South Korea, previous studies have mainly focused on the efficiency of hospitals. Yang et al. (1997) [11] analyzed technical efficiency of 31 tertiary hospitals using CCR (Charnes, Cooper and Rhodes, 1978) [12] as well as BCC (Banker, Charnes, and Cooper, 1984) [13] models, finding that the size, quality of care, value added per capita, and revenue per patient were related with their efficiency. Lee (1998) [14] estimated the efficiency of hospitals using a translog multiproduct cost function, and the empirical results revealed that the costs of labor and medical supplies accounted for approximately 70 percent of total cost, and there were economies of scale. Kim (2005) [15] explored the technical efficiency of 135 general hospitals and found that the efficiencies of the public hospitals were much lower than private hospitals. Yoo (2007) [16] insisted on the method to improve the measurement of efficiency for public hospitals using DEA, and emphasized that slacks-based measure of efficiency (SBM) should be considered to estimate more precisely the efficiencies. Oh et al. (2007) [17] measured the productivities and efficiencies of regional public hospitals from 1999 to 2002 in order to analyze the impact of separating medical practice and pharmaceutical dispensing. They found that there was no difference between before and after the reform for the separation in terms of the inefficiency. Yang (2012) [18] estimated the efficiencies using different types of models with the data of 32 regional public hospitals from 2005 to 2009 , showing that environmental factors of hospitals cause different inefficiencies. 
As described earlier, most domestic studies of hospitals have mainly focused on the analysis of the efficiency. The purpose of this paper is to measure cost minimization, capacity utilization rates and scale efficiencies of regional public hospitals from 2007 to 2010 in South Korea, while also considering the public good achieved for the disadvantaged, by adopting the number of patients as one of outputs using DEA. In this context, this paper is significant for being the first to explore the short-run average cost minimization and capacity utilization rate of all regional public hospitals in South Korea. The remainder of this paper is organized as follows: Section 2 explains a theoretical model of cost minimization and capacity utilization of the hospitals based on DEA. Section 3 presents data and the empirical results, and Section 4 provides the conclusions and discussions.

\section{Theoretical Model}

Let us assume that a hospital produce a vector of outputs, $y=\left(y_{1}, y_{2}, \cdots, y_{m}\right) \in R_{+}^{m}$, using a vector of inputs, $x=\left(x_{1}, x_{2}, \cdots, x_{n}\right) \in R_{+}^{n}$. The production possibility set is as follows:

$$
T=\{(x, y): x \text { can produce } y\}
$$

Assuming strong disposal of inputs and outputs and variable returns to scale, the true technology can be represented by the following set of production possibility:

$$
L_{\mathrm{vrS}}\left(y^{0}\right)=\left\{x: x \geq \sum_{j=1}^{J} \varphi_{j} x_{j} ; y^{0} \leq \sum_{j=1}^{J} \varphi_{j} y_{j}^{0} ; \sum_{j=1}^{J} \varphi_{j}=1(j=1, \cdots, J)\right\}
$$

where $y^{0}$ indicates the actual amount of output in Equation (2), the production possibility set under the assumption of constant returns to scale is expressed as follows:

$$
L_{\text {crs }}\left(y^{0}\right)=\left\{x: x \geq \sum_{j=1}^{J} \varphi_{j} x_{j} ; y^{0} \leq \sum_{j=1}^{J} \varphi_{j} y_{j}^{0} ; \sum_{j=1}^{J} \varphi_{j} \geq 1 \quad(j=1, \cdots, J)\right\}
$$

Whereas in the long-run, all factors of production in the hospital are variable, in the short-run, one or more inputs are fixed while others are variable. Therefore, the hospital chooses the variable inputs to minimize the cost of producing a given amount of output in the short-run. The inputs are composed of variable and fixed factors.

Equation (4) represents the minimization of the short-run total cost (SRTC), which produces a certain type of output, $y \in L$ given the vector of inputs price, $p$ as follows:

$$
\operatorname{SRTC}(p, y)=\min \left\{p^{\prime} x\left(\left(x_{v}, \overline{x_{f}}\right) \in L(y)\right)\right\}
$$

where $x_{v}$ and $\overline{x_{f}}$ indicate variable inputs, $x_{v}$, and fixed inputs, $\overline{x_{f}}$, respectively.

The minimization of the short-run total cost (SRTC) using linear programming can be expressed as follows:

$$
\begin{gathered}
\text { SRTC } y, x_{v}, \varphi(p, y)=\min \left\{p^{\prime} x_{v}+F C\right\} \\
\sum_{j=1}^{J} \varphi_{j} y_{j} \geq y \\
\sum_{j=1}^{J} \varphi_{j} x_{v(j)} \leq x_{v} \\
\sum_{j=1}^{J} \varphi_{j} x_{f(j)} \leq x_{f} \\
\sum_{j=1}^{J} \varphi_{j} \geq 0 \quad(j=1, \ldots J)
\end{gathered}
$$

Whereas short-run average cost (SRAC) is defined as adding average variable cost (total variable cost divided by output) to the average fixed cost (total fixed cost divided by output) in the short-run. $\varphi_{j}$ is a weighted density vector.

The minimization of short-run average cost (SRAC) can be derived by setting to keep the fixed element constant, and the variable factors vary. This can be expressed as follows using linear programming: 


$$
\begin{gathered}
\text { SRAC }, x_{v}, \varphi(p, y)=\min \left\{\left(\frac{P_{L}}{y} L+\frac{P_{B}}{y} B\right)+\frac{F C}{y}\right\} \\
\sum_{j=1}^{J} \varphi_{j} y_{j} \geq y, \quad j=1, \cdots, J \\
\sum_{j=1}^{J} \varphi_{j} L_{j} \leq L, \quad j=1, \cdots, J \\
\sum_{j=1}^{J} \varphi_{j} B_{j} \leq B, \quad j=1, \cdots, J \\
\sum_{j=1}^{J} \varphi_{j} K_{j} \leq K, \quad j=1, \cdots, J \\
\sum_{j=1}^{J} \varphi_{j} \geq 0, \quad j=1, \cdots, J
\end{gathered}
$$

Here, variable factors are labor $(L)$ and bed $(B)$, and a fixed element is capital stock $(K) . P_{L}$ and $P_{B}$ denote the price of labor and bed, respectively.

The maximum output which minimizes the short-run average cost can be obtained from the minimization point in Equation (6). The capacity utilization rate is the ratio between the maximum output minimizing the average cost and the actual output. Thus, the short-run capacitv utilization (SCU) ratio can be derived by comparing the maximum output $\left(y^{*}\right)$ and the actual output $\left(y^{0}\right)$ as follows:

$$
\operatorname{SCU}=\frac{y^{0}}{y^{*}}
$$

If $y^{0}$ is equal to $y^{*} \quad(\mathrm{SCU}=1)$, it represents the minimization point of the short-run average cost. If $y^{0}$ is less than $y^{*} \quad(\mathrm{SCU}<1)$. the average cost is in the decreasing area in the short-run average cost curve. which indicates that hospitals are able to reduce the average cost per unit by increasing variable inputs. Whereas if $y^{0}$ is greater than $y^{*} \quad(\mathrm{SCU}>1)$, the average cost is in the increasing area in the short-run average cost curve, which indicates that hospitals are able to reduce the average cost per unit by decreasing variable inputs.

Figure 1 shows the relation between the short-run average cost and the capacity utilization rate ${ }^{1}$.

In Figure 1, a point $b$ is the minimum point of the short-run average cost. The left hand side of the minimum point $b$ is the decreasing area of the short-run average cost curve whereas the right hand side of the point $b$ is the increasing area in the short-run average cost curve. Therefore, if the hospital runs at a point $a$, SCU would be less than one (1), while if the hospital runs at a point $c$. SCU would be greater than one (1).

Short-run scale efficiency (SSE) can be defined as the ratio between the minimum average cost (SRAC*) and the actual average cost (SRAC) in the short-run, hence, it can be represented as follows:

$$
\text { SSE }=\frac{\text { SRAC }^{*}}{\text { SRAC }}
$$

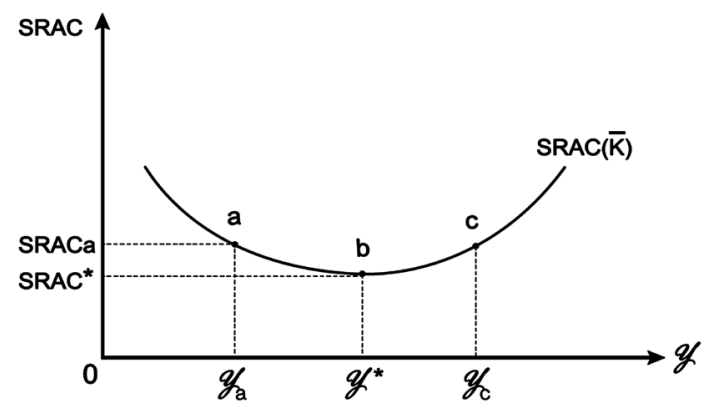

Figure 1. Short-run average cost and capacity utilization rate.

${ }^{1}$ The figure is modified of "short-run average cost curve and capacity utilization rate” by Kang (2013) [19]. 
The short-run scale efficiency (SSE) is less than or equal to 1 (one) since SRAC in Equation (8) is the actual average cost in the short-run.

\section{Data and Empirical Result}

\subsection{Data}

The data are obtained from financial statements (Balance sheets \& Income statements) and final accounts from the Korean Association of Regional Public Hospitals (KARPH) during the period from 2007 to $2010^{2}$. The total cost of a hospital is measured as a sum of the recurrent cost of hospital in a given year. Both the adjusted number of patients and value added variables are outputs. While adjusted number of patients variable includes the total number of outpatients and the total number of inpatients in a given year, value added variable contains income and loss before income taxes, labor charges, net interest expenses, rental expenses, and taxes as well as public dues. The number of doctors, nurses, and beds are used as inputs. Capital stock (tangible fixed assets) is utilized as a fixed input, which excludes depreciation. Tangible fixed assets include land, buildings, land improvements, machinery, delivery equipment or vehicles, and medical equipment.

All price variables are expressed at constant prices based on 2010 using the Consumer Price Index (CPI). The method to estimate these variables are shown in Table 1.

\subsection{Empirical Result}

This study intends to seek for the cost minimization and capacity utilization rate over 34 regional public hospitals. When it comes to reduction of the cost, it is plausible to save the cost via enlargement or reduction of input factors for hospitals. It, then, can define the average cost for each hospital to determine whether a hospital runs at the minimum average cost.

The annual capacity utilization ratio of the regional public hospitals, across the nation, showed 0.49 on average using adjusted number of patients as an output in Table 2. Jeju showed the highest capacity utilization ratio, and Seoul (0.93), Chungju (0.84), Anseong (0.76), Seogwipo (0.70), and Busan (0.69) followed after Jeju while Suncheon (0.19) and Yeongwol (0.19) showed the lowest capacity utilization ratio. This implies that almost all regional public hospitals in South Korea have not run at full capacity during the same period.

Since the capacity utilization ratio of these hospitals, except for Jeju, ranged from 0.19 to 0.93 , most of them were in the diminishing area of the short-run average cost curve, which means that their average cost decreases as their output (adjusted number of patients) increases. This maybe because the size of these hospitals is so small that they can relatively easily reduce their average cost in the short-run when increasing their output.

Excepting Jeju, all of these hospitals showed comparatively low levels of the short-run scale efficiency. Jeju represented one (1); Anseong (0.91), Icheon (0.88), Seoul (0.87), and Chungju (0.87) followed Jeju whereas Suncheon (0.39), Gongju (0.39), Yeongwol (0.38), and Uljin (0.36) showed low levels of the short-run scale ef-

\section{Table 1. Method to estimate variables.}

\begin{tabular}{|c|c|}
\hline Variables & Estimation method \\
\hline AP & (Annual number of inpatients) $+\{$ (outpatient revenue) $\times$ (annual number of outpatients) $\} /($ inpatient revenue) $\}$ \\
\hline VA & (Labor charge) + (rental expense) + (net interest expenses) + (income and loss before income taxes) $+($ tax and public dues) \\
\hline TC & (medical cost) $+($ non medical cost) \\
\hline ND & (Medical specialists) + (general practitioners) + (dentists) + (oriental doctors) + (interns) + (residents) \\
\hline NN & (nurses) + (nurses’ aides) \\
\hline $\begin{array}{l}\text { Capital stock } \\
\text { (TFA) }\end{array}$ & $\begin{aligned} \begin{array}{l}\{(\text { Land })+(\text { buildings })+(\text { land improvements })+(\text { machinery })+(\text { delivery equipment or vehicles })+(\text { medical equipment }) \\
+(\text { equipment })+(\text { construction in progress })\}-(\text { accumulated amount of depreciation })\end{array}\end{aligned}$ \\
\hline
\end{tabular}

a) AP, VA, TC, ND, NN, and TFA mean adjusted number of patients, value added, total cost, number of doctors, number of nurses, and tangible fixed assets, respectively; b) The estimation of method of VA is based on the addition method of the Bank of Korea (BOK).

${ }^{2}$ The latest data from KARPH are only publicly available up to 2010. Even though we could not compile the data from Diagnosis Related Group Payment System (DRGs) (which have been implemented in the public hospitals since 2012), it may give more realistic information about economic performance of the regional public hospitals. 
Table 2. Capacity utilization and cost minimization using adjusted number of patients (2007-2010) (unit: million won).

\begin{tabular}{|c|c|c|c|c|}
\hline Hospitals & Cap-U & SRTC ${ }^{*}$ & SRAC $^{*}$ & SSE \\
\hline Gangjin & 0.44 & 11,332 & 0.94 & 0.67 \\
\hline Suncheon & 0.19 & 28,461 & 0.53 & 0.39 \\
\hline Seogiwipo & 0.70 & 26,002 & 1.05 & 0.75 \\
\hline Jeju & 1.00 & 10,722 & 1.36 & 1.00 \\
\hline Jinju & 0.33 & 37,119 & 0.66 & 0.51 \\
\hline Masan & 0.42 & 37,595 & 0.81 & 0.61 \\
\hline Uljin & 0.21 & 17,438 & 0.49 & 0.36 \\
\hline Gimcheon & 0.43 & 28,075 & 0.75 & 0.57 \\
\hline Andong & 0.40 & 34,701 & 0.72 & 0.58 \\
\hline Pohang & 0.30 & 29,379 & 0.60 & 0.47 \\
\hline Mokpo & 0.49 & 16,507 & 0.78 & 0.58 \\
\hline Namwon & 0.38 & 16,196 & 0.76 & 0.52 \\
\hline Gunsan & 0.57 & 57,054 & 0.94 & 0.63 \\
\hline Seosan & 0.39 & 42,679 & 0.80 & 0.61 \\
\hline Hongseong & 0.48 & 65,093 & 1.08 & 0.61 \\
\hline Gongju & 0.26 & 62,139 & 1.08 & 0.39 \\
\hline Cheonan & 0.49 & 15,339 & 0.86 & 0.66 \\
\hline Chungju & 0.84 & 16,905 & 0.72 & 0.87 \\
\hline Cheongju & 0.50 & 45,913 & 0.82 & 0.64 \\
\hline Seoul & 0.93 & 71,070 & 1.16 & 0.87 \\
\hline Busan & 0.69 & 58,101 & 0.95 & 0.72 \\
\hline Daegu & 0.48 & 43,720 & 0.71 & 0.56 \\
\hline Incheon & 0.50 & 46,391 & 0.81 & 0.62 \\
\hline Wonju & 0.37 & 26,767 & 0.70 & 0.50 \\
\hline Gangneung & 0.48 & 14,274 & 0.91 & 0.68 \\
\hline Sokcho & 0.40 & 18,025 & 0.72 & 0.57 \\
\hline Yeongwol & 0.19 & 21,087 & 0.50 & 0.38 \\
\hline Samcheok & 0.31 & 18,450 & 0.64 & 0.46 \\
\hline Suwon & 0.27 & 35,194 & 0.64 & 0.48 \\
\hline Uijeongbu & 0.62 & 27,012 & 0.98 & 0.73 \\
\hline Icheon & 0.66 & 20,453 & 1.16 & 0.88 \\
\hline Anseong & 0.76 & 18,421 & 1.25 & 0.91 \\
\hline Paju & 0.56 & 40,761 & 0.99 & 0.79 \\
\hline Pocheon & 0.67 & 21,412 & 1.05 & 0.79 \\
\hline Average & 0.49 & 32,640 & 0.85 & 0.63 \\
\hline
\end{tabular}

a) Cap-U, SRTC* ${ }^{*}$ SRAC*, and SSE denote short-run capacity-utilization, the minimum total cost in the short-run, the minimum average cost in the short-run, and short-run scale efficiency, respectively.

ficiency below 0.40. It means that except for Jeju, almost all these public hospitals were far away from the minimum average cost in the short-run during the same period by showing under one (1).

The empirical result above indicates that only Jeju has operated at the highest level of the capacity utilization whereas almost all regional public hospitals have not operated at full capacity during the same period. Also, it indicates that only Jeju has achieved the cost minimization but others have fallen in the decreasing area in the short-run average cost curve.

The annual capacity utilization ratio, using value added as an output, of the regional public hospitals across the nation showed 0.56 on average in Table 3 . Even though the capacity utilization ratio of the regional public hospitals using value added was a bit higher compared to the empirical result using an adjusted number of patients, Uljin (0.23), Yeongwol (0.27), and Gongju (0.29) still represented the low levels of capacity utilization ratio. Excepting Jeju and Seoul, almost all regional public hospitals have operated below full capacity since the capacity utilization rate of these hospitals, except for Jeju and Seoul, ranged from 0.23 to 0.85 during the same 
Table 3. Capacity utilization and cost minimization using value added (2007-2010) (unit: million won).

\begin{tabular}{|c|c|c|c|c|}
\hline Hospitals & Cap-U & SRTC $^{*}$ & SRAC ${ }^{*}$ & SSE \\
\hline Gangjin & 0.48 & 10,382 & 1.66 & 0.69 \\
\hline Suncheon & 0.33 & 19,447 & 0.98 & 0.41 \\
\hline Seogiwipo & 0.71 & 27,897 & 2.02 & 0.81 \\
\hline Jeju & 1.00 & 10,722 & 2.60 & 1.00 \\
\hline Jinju & 0.52 & 27,445 & 1.27 & 0.55 \\
\hline Masan & 0.66 & 31,032 & 1.65 & 0.74 \\
\hline Uljin & 0.23 & 16,907 & 0.96 & 0.36 \\
\hline Gimcheon & 0.47 & 28,994 & 1.50 & 0.60 \\
\hline Andong & 0.45 & 33,990 & 1.48 & 0.61 \\
\hline Pohang & 0.37 & 27,190 & 1.21 & 0.51 \\
\hline Mokpo & 0.48 & 17,470 & 1.47 & 0.58 \\
\hline Namwon & 0.64 & 45,869 & 1.54 & 0.77 \\
\hline Gunsan & 0.65 & 55,990 & 1.92 & 0.66 \\
\hline Seosan & 0.48 & 40,510 & 1.63 & 0.70 \\
\hline Hongseong & 0.59 & 62,105 & 2.21 & 0.68 \\
\hline Gongju & 0.29 & 62,572 & 2.26 & 0.43 \\
\hline Cheonan & 0.63 & 14,351 & 1.47 & 0.75 \\
\hline Chungju & 0.84 & 16,831 & 1.31 & 0.85 \\
\hline Cheongju & 0.67 & 44,316 & 1.77 & 0.76 \\
\hline Seoul & 1.00 & 78,782 & 2.47 & 1.00 \\
\hline Busan & 0.72 & 57,220 & 1.89 & 0.70 \\
\hline Daegu & 0.58 & 45,916 & 1.47 & 0.67 \\
\hline Incheon & 0.60 & 44,698 & 1.73 & 0.68 \\
\hline Wonju & 0.58 & 25,837 & 1.39 & 0.73 \\
\hline Gangneung & 0.50 & 12,760 & 1.60 & 0.63 \\
\hline Sokcho & 0.41 & 17,853 & 1.32 & 0.56 \\
\hline Yeongwol & 0.27 & 17,436 & 1.02 & 0.39 \\
\hline Samcheok & 0.34 & 18,481 & 1.22 & 0.51 \\
\hline Suwon & 0.40 & 27,645 & 1.30 & 0.51 \\
\hline Uijeongbu & 0.62 & 24,851 & 1.83 & 0.67 \\
\hline Icheon & 0.74 & 18,188 & 2.05 & 0.86 \\
\hline Anseong & 0.85 & 16,308 & 2.21 & 0.90 \\
\hline Paju & 0.39 & 39,671 & 2.32 & 0.51 \\
\hline Pocheon & 0.59 & 21,599 & 1.95 & 0.69 \\
\hline Average & 0.56 & 31,222 & 1.67 & 0.66 \\
\hline
\end{tabular}

a) Cap-U, SRTC*, SRAC*, and SSE denote short-run capacity-utilization, the minimum total cost in the short-run, the minimum average cost in the short-run, and short-run scale efficiency, respectively.

period. This means Jeju and Seoul have reached the cost minimization but others have failed to achieve the same ratio of decreasing average cost, which means most of them were in the diminishing area in the short-run average cost curve as their output (value added) increases.

Most of these hospitals showed comparatively low levels of the short-run scale efficiency. Jeju and Seoul represented one (1); Anseong (0.90), Icheon (0.86), and Chungju (0.85) followed Jeju and Seoul whereas Uljin (0.36) and Yeongwol (0.39) showed low levels of the short-run scale efficiency below 0.40. It means that except for Jeju and Seoul, many of them were far away from the minimum average cost in the short-run during the same period by showing under one (1).

The empirical result above illustrates that only Jeju and Seoul have run at full capacity whereas most of the regional public hospitals have not during the same period. In addition, it illustrates that only Jeju and Seoul have reached the cost minimization but others have been in the decreasing area in the short-run average cost curve. 


\section{Conclusions and Discussion}

This paper estimated the cost minimization and capacity utilization of 34 regional public hospitals in South Korea from 2007 to 2010 utilizing DEA. During the same period, we found that the annual capacity utilization ratio, using adjusted number of patients as an output was 0.49 , and the figure using value added as an output was 0.56 , on average. Only Jeju showed the highest level of the capacity utilization regardless of output type. In other words, almost all these public hospitals, except for Jeju, have not operated at full capacity during the time period.

Also, we learned that the annual short-run scale efficiency using adjusted number of patients as an output was 0.63 , and the figure using value added as an output was 0.66 , on average. When it comes to the annual short-run scale efficiency using adjusted number of patients as an output, except for Jeju, almost all these public hospitals have been far away from the minimum average cost showing under one (1). When it comes to the annual short-run scale efficiency using value added, except for Jeju and Seoul, most of these public hospitals have failed to reach the minimum average cost showing under one (1). Thus, only Jeju showed the optimal short-run scale efficiency regardless of output type by representing one (1).

It is important whether an individual regional public hospital hires a proper amount of workers and medical equipment under the optimal size, since the capacity utilization rate allows each hospital to benefit from the information which indicates what kind of resource is a waste. Although this study has a limitation to offer in terms of a comprehensive analysis of these hospitals, future research may consider some other important data such as the quality of medical service or DRGs.

As the empirical results above showed, only Jeju has achieved not only the cost minimization but also the full capacity utilization and the optimal scale efficiency in the short-run during the time period, regardless of the output type. It illustrates that almost all regional public hospitals, except for Jeju, have not run at full capacity, and the short-run average cost of operation of the hospitals has been decreasing, during the same period. It also implies that there is the potential to possibly increase their capacity utilization ratio by utilizing unused facilities. However, taking circumstances into consideration, such as the fact that the regional public hospitals have to have invested in certain types of capital such as acute care facilities, even if these facilities remain unused as a necessary role to serve potential patients, we need to be careful when estimating the economic performance of public hospitals when considering its unique role in serving the public as a whole.

\section{References}

[1] OECD (2013) OECD Health Data 2013.

[2] Cassels, J.M. (1937) Excess Capacity and Monopolistic Competition. Quarterly Journal of Economics, 51, 426-443. http://dx.doi.org/10.2307/1884835

[3] Klein, L.R. (1960) Some Theoretical Issues in the Measurement of Capacity. Econometrica, 28, 272-286. http://dx.doi.org/10.2307/1907721

[4] Johansen, L. (1968) Production Functions and the Concept of Capacity, Recherches Recentes sur la Fonction de Production, Collection. Economie Mathematique et Econometrie, 2, 49-72.

[5] Färe, R. (1984) On the Existence of Plant Capacity. International Econometric Review, 25, 209-213. http://dx.doi.org/10.2307/2648875

[6] Färe, R., Grosskopf, S. and Kokkenlenberg. E. (1989) Measuring Plant Capacity Utilization and Technical Change: A Nonparametric Approach. International Economic Review, 30, 655-666. http://dx.doi.org/10.2307/2526781

[7] Eilon, S. and Soesan, J. (1976) Reflections on Measurement and Evaluation. In: Eilon, S., Gold, B. and Soesan J., Eds., Applied Productivity Analysis for Industry, Pergamon Press, Oxford, 115-133.

[8] Farrell, M.J. (1957) The Measurement of Productive. Journal of the Royal Statistical Society, Series A, CXX, 3, 253290.

[9] Shepard, R.W. (1970) Theory of Cost and Production Function. Princeton University Press, Princeton.

[10] Berndt, E. and Morrison, C. (1981) Capacity Utilization Measures: Underlying Theory and an Alternative Approach. American Economic Review, 71, 48-52.

[11] Yang, D.H., Suh, W.S. and Park, K.H. (1997) A Study on Measuring Hospital Efficiency and Analyzing Its Determinants in Tertiary Hospitals: Data Envelopment Analysis. Korea Society of Hospital Administration, 2, 183-202.

[12] Charnes, A., Cooper, W.W. and Rhodes, E. (1978) Measuring the Efficiency of Decision-Making Units. European Journal of Operational Research, 2, 429-444. http://dx.doi.org/10.1016/0377-2217(78)90138-8 
[13] Banker, R., Charnes, A. and Cooper, W.W. (1984) Some Models for Estimating Technical and Scale Inefficiencies in Data Envelopment Analysis. Management Science, 30, 1078-1092. http://dx.doi.org/10.1287/mnsc.30.9.1078

[14] Lee, J.H. (1998) A Study on Estimating of the Cost Function of Hospitals. The Korea Public Health Association, 123123.

[15] Kim, J.H. (2005) Factors Affecting Technical Efficiency of Hospitals and Policy Implications in Korea. Industrial Economics Association, 18, 2897-2921.

[16] Yoo, G.R. (2007) Methodological Improvement of Measurement of Efficiency for Public Hospitals. Korean Journal of Local Government \& Administration Studies, 21, 43-57.

[17] Oh, D.W., Lee, J.H. and Min, I.S. (2007) Analysis on Efficiency and Productivity of Korean Regional Public Hospital between before and after the Separation of Dispensary from Medical Practice. The Korean Journal of Health Economics and Policy, 13, 173-198.

[18] Yang, D.H. (2012) Analysis on the Difference in Efficiencies between Environmental Factors of Regional Public Hospitals in Korea Using Supper-Efficiency Model. The Korea Contents Association, 12, 284-294. http://dx.doi.org/10.5392/JKCA.2012.12.07.284

[19] Kang, S.M. (2013) Measurement of Short-Run Cost Minimization, and Capacity Utilization in Logistics and Warehousing Firms. Korea Productivity Association, 27, 169-192. 
Scientific Research Publishing (SCIRP) is one of the largest Open Access journal publishers. It is currently publishing more than 200 open access, online, peer-reviewed journals covering a wide range of academic disciplines. SCIRP serves the worldwide academic communities and contributes to the progress and application of science with its publication.

Other selected journals from SCIRP are listed as below. Submit your manuscript to us via either submit@scirp.org or Online Submission Portal.
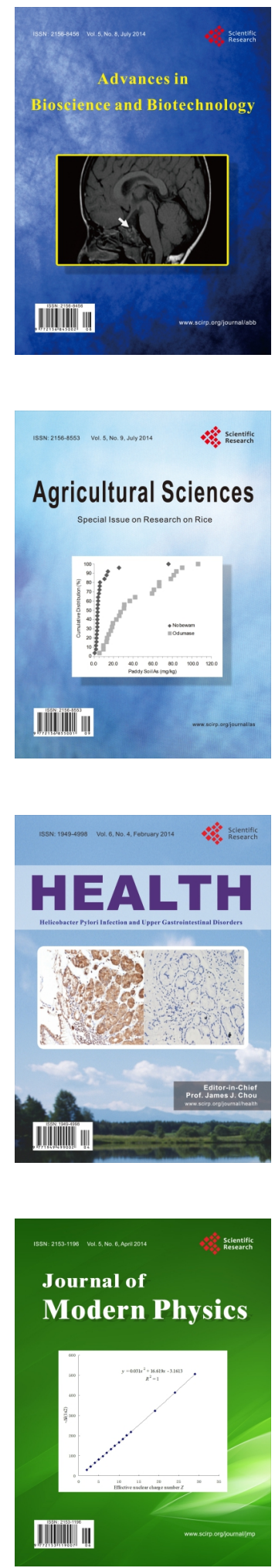
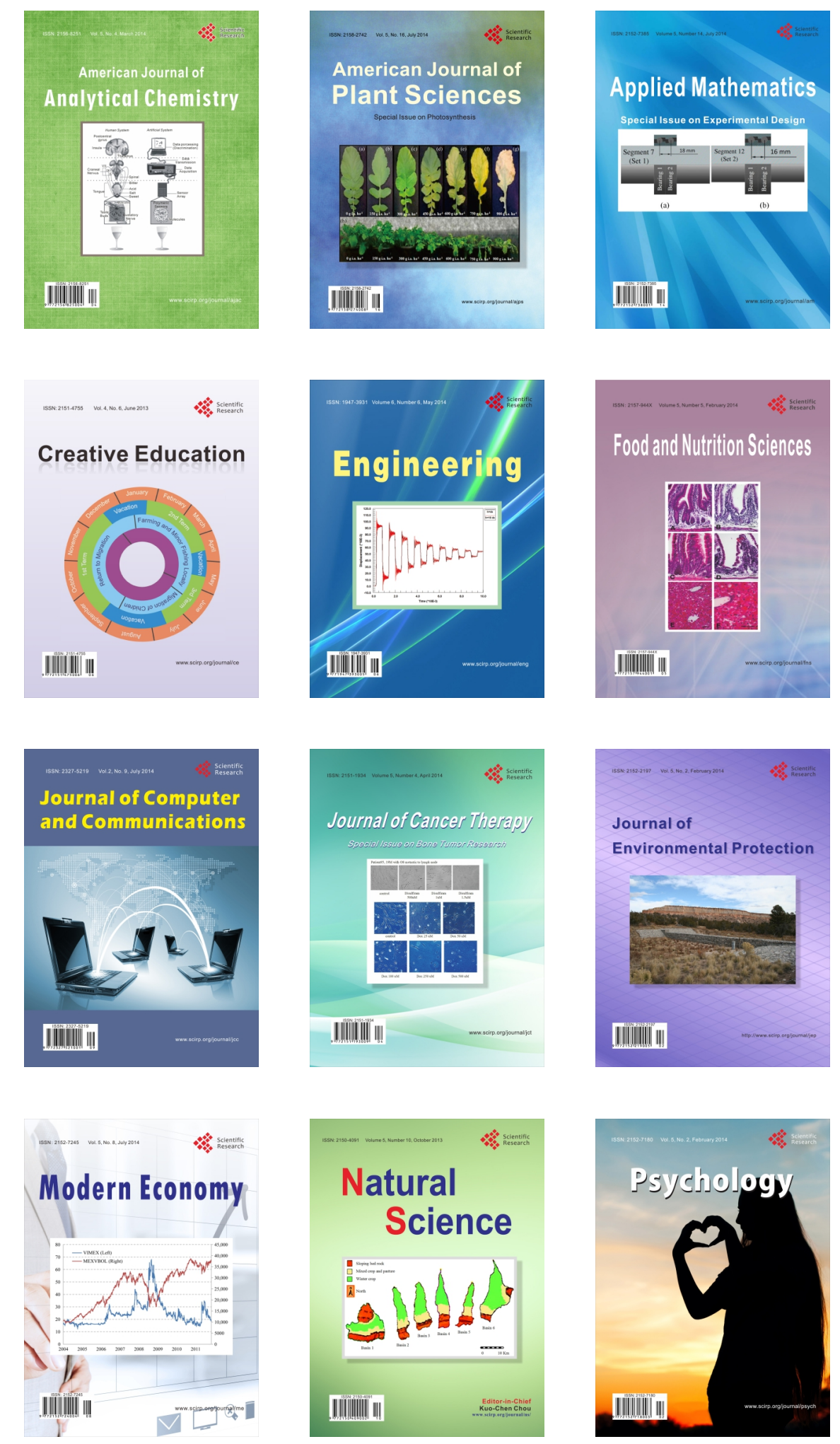